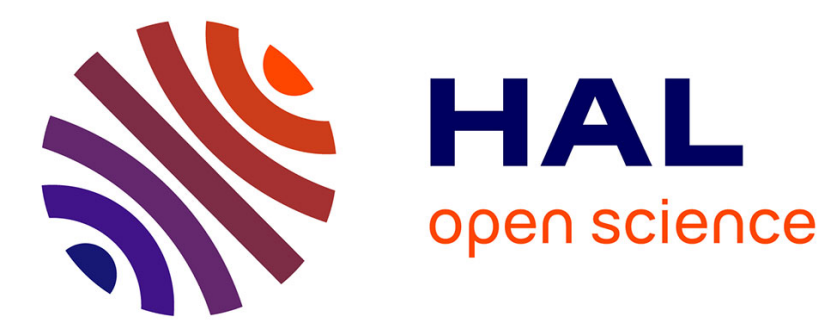

\title{
Scientific community Celebration of a chemical centenary
}

\author{
Yi Yan Yang, Julien Nicolas
}

\section{To cite this version:}

Yi Yan Yang, Julien Nicolas. Scientific community Celebration of a chemical centenary. Nature Chemistry, 2019, 11 (10), pp.870-871. 10.1038/s41557-019-0334-6 . hal-02325164

\section{HAL Id: hal-02325164 \\ https://hal.science/hal-02325164}

Submitted on 22 Oct 2019

HAL is a multi-disciplinary open access archive for the deposit and dissemination of scientific research documents, whether they are published or not. The documents may come from teaching and research institutions in France or abroad, or from public or private research centers.
L'archive ouverte pluridisciplinaire HAL, est destinée au dépôt et à la diffusion de documents scientifiques de niveau recherche, publiés ou non, émanant des établissements d'enseignement et de recherche français ou étrangers, des laboratoires publics ou privés. 
Scientific community

Celebration of a chemical centenary

Yi Yan Yang ${ }^{1}$ and Julien Nicolas ${ }^{2}$

To celebrate the centenary of the International Union of Pure and Applied Chemistry in July 2019, the $47^{\text {th }}$ IUPAC World Chemistry Congress took place in Paris. Its program reflected how chemistry can help to address today and tomorrow's most challenging issues, in particular relevant to human well-being and sustainable development.

The world faces many challenges to which chemistry can help provide solutions, spanning from environmental pollution and climate change to human health and the growing of demand for scarce resources, to mention just a few. These issues are very different from those faced by chemists at the start of the 20th century, and which had led to the creation of the International Union of Pure and Applied Chemistry, in Paris in July 1919. Chemistry was a well-established science, yet several points of confusion within the field (including a proliferation of names and notations for chemical species) hindered progress. Since its 
creation in 1919, IUPAC has endeavoured to foster communication between chemists, internationally, across fields, and between academia and industry.

Held at the Palais des Congrès in Paris from July 7-12, 2019, the $47^{\text {th }}$ IUPAC World Chemistry Congress suitably celebrated the centenary of the Union by gathering chemists with very diverse backgrounds and working in varied areas. The program, organized around a number of societal issues, highlighting "Chemistry for life", "Chemistry for energy and resources" and "Chemistry for the environment" as the three main themes. A separate session was devoted to "Chemistry across the themes", reflecting how interwoven these three topics are. In parallel, chemical education was discussed, a symposium was dedicated to the place of chemistry in society, and a number of other sessions gave communities — such as young chemists and women - the opportunity to host discussions in smaller groups to focus on their needs and interests. In celebration of the centenary of the Union, symposia were also held that explored the history of the field in general and of the IUPAC in particular.

Reflecting the breadth of topics covered throughout the congress, eight plenary lectures provided plenty of food for thought on a variety of topics including translational research in therapeutic delivery (Kazunori Kataoka, Tokyo University), 2D electrocatalysts for $\mathrm{CO}_{2}$ reduction (Yi Xie, Hefei University) and advanced macromolecular engineering (Krzysztof Matyjaszewski, Carnegie-Mellon University) . A highlight of the congress was a morning with two consecutive such plenary lectures. Zhenan Bao (Stanford University) first gave an overview of her outstanding work on the design of organic electronic materials to mimic skin functions that can find new applications in medical devices, robotics and wearable electronics. Her talk was followed by "Three tenors for an ode to soft machines", a presentation 
performed in music by the three 2016 Nobel Laureates in Chemistry: Jean-Pierre Sauvage (University of Strasbourg), J. Fraser Stoddart (Northwestern University) and Ben L. Feringa (University of Groningen), who presented a brief history of their inspiring work on molecular machines. These sessions nicely illustrated how creative chemistry can directly lead to practical applications.

A long-standing goal shared by numerous academic and industrial chemical laboratories is the treatment severe diseases such as cancer, and a variety of innovative drug-delivery strategies were showcased during the week. Drug-loaded nanocarriers, such as polymer nanoparticles or liposomes, have shown promising results and have even been assessed in advanced clinical trials but so far only very few such products have been marketed. Furthermore, nanocarriers that enable the targeted delivery of their cargo (for example by functionalizing surfaces with active ligands that promote the accumulation of the carriers, and in turn the drugs, into the tumor), are thought to improve the therapeutic efficacy of the drug they deliver. However, their clinical translation has not occurred yet. Among the approaches explored to promote such bench-to-bedside translation, Dan Peer (Tel Aviv University) presented RNA-loaded lipid nanoparticles — prepared using microfluidic mixing in a highly reproducible, modular manner - that are decorated on their surface by monoclonal antibodies (mAbs) for efficient targeting (Figure 1).

The delivery of anticancer drugs using nanocarriers was nicely illustrated by Paula T. Hammond (MIT), who uses layer-by-layer coatings to achieve sequential release of therapeutics. Jesus Santamaria (University of Zaragoza) presented a different approach, in which catalytic nanoparticles serve as bio-orthogonal tools that can directly act at the diseased 
site to alter the chemistry inside the tumor. This enables for instance the local depletion of nutrients to hinder the rapid replication of cancerous cells, or the creation of toxic species in situ.

Designing biomimetic and biofunctional nanoparticulate systems to reach cell-like synthetic nano-objects was a common goal shared by several speakers, including Sebastien Lecommandoux (University of Bordeaux), Jan Van Hest (University of Eindhoven) and MinHui Li (Paris Sciences and Letters University). All three presented recent results on stimuliresponsive polymer-based structures: polymersomes that are able to pop in response to light irradiation (Lecommandoux); compartmentalized polymersomes that gain motility upon conversion of ATP (Van Hest); and photo-, redox-, $\mathrm{CO}_{2^{-}}$and $\mathrm{pH}$-sensitive moieties that endow polymersomes with stimuli-activated openings (Li).

Ensuring worldwide access to available and affordable energy is today a key challenge for humanity. The uneven global distribution of energy sources means that a drastic change is required in the way we generate and supply energy. A number of key topics were covered at this congress that focused on addressing energy challenges, including new approaches for electrochemical energy storage and conversion, turning solar energy to fuels via photosynthesis, multi-Terawatt clean photovoltaic energy conversion, the development of renewable resources, innovations in nuclear energy; the increasing role of computational design was also discussed. For example, Angela Belcher (MIT) presented in her plenary talk her elegant work on genetically engineering viruses to make biological hybrid nanomaterials for building high-power battery, clean fuel cells and more efficient solar cells. Daniel Nocera (Harvard University) discussed the synthesis of an artificial leaf to mimic natural photosynthesis and split water to hydrogen and oxygen using sunlight, as well as a bionic leaf able to convert hydrogen and $\mathrm{CO}_{2}$ from air into biomass and liquid fuels. He showed that 
combining these two processes — that is, using hydrogen produced from the artificial leaf in the $\mathrm{CO}_{2}$ conversion - closes an entire artificial photosynthetic cycle with a higher yield than that of natural photosynthesis.

A source of great environmental concern is the widespread use of plastics. Even though they are immensely important in our everyday life, nearly all of them derive from non-renewable resources and only a tiny amount is eventually recycled. Marc Hillmyer (University of Minnesota) discussed efforts from the National Science Foundation Center for Sustainable Polymer (CSP, https://csp.umn.edu) that draws together researchers from seven universities and more than 30 companies from across the US to transform how plastics are synthesized and recycled. This innovative research is focused on several relevant steps: the sustainable conversion of biomass to polymer ingredients, the design of high-performance sustainable plastics and elastomers, and the sustainable degradation, chemical recycling and compatibilization of polymers. Another major environmental concern is water and air contamination, which was reflected through several approaches to the development of membranes. Thomas Sabu (Mahatma Gandhi University) for example described highperformance, functional, and eco-friendly nanomaterials made from inexpensive carbohydrate polymer-based biomasses, which show great promise as filter materials for water purification.

The broad diversity of the topics discussed during the week and the numerous questions and discussions between the speakers and the attendees reflected the confluence of tremendous efforts and vision from the community towards tackling today's and tomorrow's societal challenges. Despite the progress we have made in the search for alternative energy sources, innovative ways to reduce and/or convert $\mathrm{CO}_{2}$, new therapeutics to tackle major diseases such 
as cancer and multidrug-resistant infections, tremendous efforts will still be needed to bring in together talents with expertise in multidisciplinary areas ranging from chemistry, biology, engineering, medicine to, increasingly, artificial intelligence. Emerging areas such as the development of new and clean protein sources also require resources and efforts to thrive, and in turn be translated into practical impact.

In 1919 European chemists from both academia and industry had gathered in Paris and formed IUPAC, with the aim of fostering worldwide communication within the field. A century later, the breadth and depth of topics covered at this 47th Congress reflects how far the field of chemistry has come, and how the scale and urgency of the challenges that it faces have changed. More than ever, there is a need for chemists to engage in not only international but also interdisciplinary communication. 
Authors' affiliations

Yi Yan Yang ${ }^{1}$ and Julien Nicolas ${ }^{2}$

${ }^{1}$ Institute of Bioengineering and Nanotechnology (IBN), Agency for Science, Technology and Research (A*STAR), 31 Biopolis Way, The Nanos, 08-07, Singapore 138669.

\section{yyyang@ibn.a-star.edu.sg}

${ }^{2}$ Institut Galien Paris-Sud, UMR CNRS 8612, Univ Paris-Sud/Paris-Saclay, Faculté de Pharmacie, 5 rue Jean-Baptiste Clément, F-92296 Châtenay-Malabry Cedex, France. julien.nicolas@u-psud.fr

Twitter: @julnicolas

a

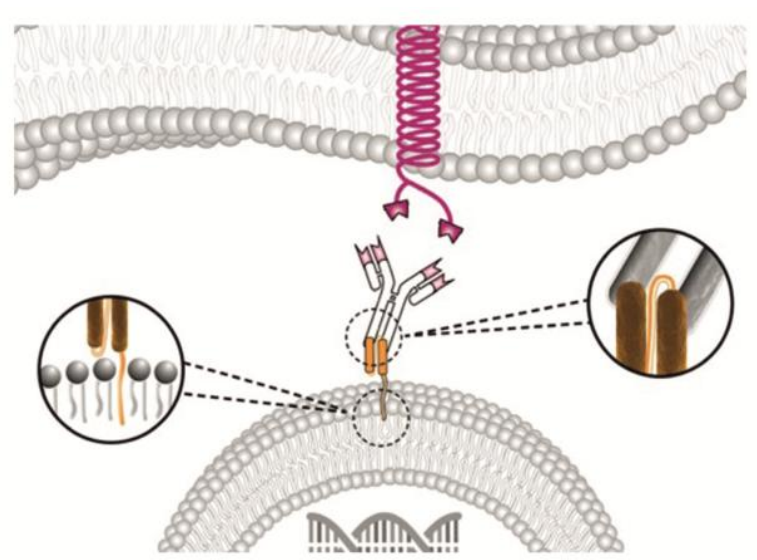

b

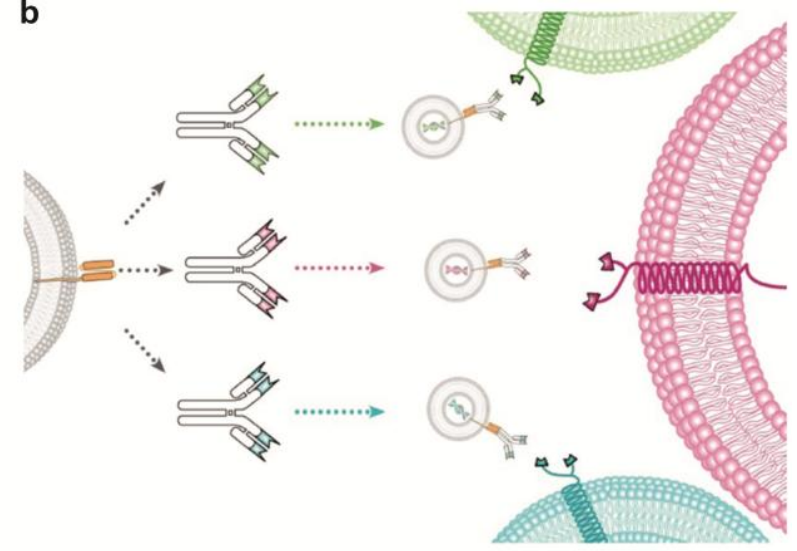

Figure 1 | A modular nanoparticulate platform for targeted therapeutics. a, Schematic illustration of the membrane-anchored lipoprotein into RNA-loaded LPNs that interact with the antibody Fc domain. b, Schematic illustration of the versatility of the targeting platform, made possible by coating RNA-loaded LNPs with diverse mAbs to target different cell subsets. Adapted with permission from Nature Nanotechnology 2018, 13, 214. 